\title{
A cultura no palco da economia: história, conceitos e aplicações no setor turístico da Ilha Mém de Sá (SE)
}

\author{
Culture in economy: history, concepts and applications in the tourism \\ sector of Mém de Sá Island (SE)
}

\section{LA cultura en la economía: historia, conceptos y aplicaciones en el sector turístico en la Isla Mém de Sá (SE)}

\author{
Janaina Cardoso de Mello \\ Professora Adjunta do DHI do Instituto Federal de Sergipe (IFS) \\ Mestrado em Memória Social na Universidade Federal do Estado do Rio de Janeiro (UNIRIO); \\ Doutorado em História Social na Universidade Federal do Rio de Janeiro (UFRJ) \\ Mestranda em Turismo no Instituto Federal de Sergipe (IFS) \\ janainamello@uol.com.br \\ Estefanni Patricia Santos Silva \\ Especialista em Arte e Educação na Faculdade São Luis de França \\ Mestranda em Turismo no Instituto Federal de Sergipe (IFS) \\ estefanni.p@gmail.com \\ Fabiana Faxina \\ Professora do Instituto Federal de Sergipe (IFS)
}

Mestre em Desenvolvimento Regional e Meio Ambiente na Universidade de Santa Cruz (UESC)

Doutora em Desenvolvimento e Meio Ambiente na Universidade de Santa Cruz (UESC)

fabi_fa@hotmail.com

Data de Submissão: 05/06/2017 - Data de Aceitação: 26/02/2018

Resumo: O artigo tem como primeiro objetivo apresentar os conceitos de "políticas públicas", "políticas
culturais", "economia da cultura", "indústrias culturais", "indústrias criativas", "economia criativa"
em sua historicidade e relacionamentos existentes entre eles. O segundo momento busca analisar os
números dos investimentos das políticas culturais perpassando os orçamentos do Programa Monumenta
e do Prodetur. O estudo de caso do Turismo de Base Comunitária da Ilha Mem de Sá, no município
sergipano de Itaporanga da Ajuda, finaliza a aplicação do corpus teórico à experiência prática de um
modelo de turismo capaz de dialogar profundamente com o viés econômico da criatividade da cultura. A 
metodologia caracteriza-se como quali-quantitativa no levantamento bibliográfico e estatístico para análise comparativa, compreendendo ainda um trabalho de campo. A visão romântica da cultura que mantém um povo ligado à sua terra, que está solidificada nos elos de transmissão familiar sem a percepção de um retorno financeiro tem se fragmentado frente aos efeitos da globalização com ofertas sedutoras de ganho econômico. A economia, portanto, torna-se emblemática para repensar esse quadro a partir do turismo. Palavras-chave: economia da cultura; patrimônio cultural; turismo cultural.

Abstract: The main goal of this article is to introduce the concepts of "public policy", "cultural policies", "economy of culture", "cultural industries", and "creative industries", "creative economy" in terms of their history, and the relationships between them. Secondly, it aims to analyze the numbers of investments on cultural policies, taking in the budgets of the Monumenta and Prodetur Program. This case study of community-based Tourism on the island Mem de Sá, in the municipality of Itaporanga da Ajuda in Sergipe, completes the application of the theoretical corpus to the practical experience of a tourism model able to engaging deeply with the economic bias of creativity of culture. Qualitative and quantitative methods were used in the bibliographic review, and comparative analysis in the statistical analysis. It also includes field work. The romantic vision of culture that keeps people connected to their land, which is solidified in the links of family transmission links without any perception of financial return, has become fragmented due to the effects of globalization, with tempting offers of economic gain. The economy, therefore, becomes iconic when rethinking this tourism scenario. Keywords: Economics of culture; cultural heritage; cultural tourism.

Resumen: El artículo tiene como primer objetivo introducir los conceptos de "política pública", "políticas culturales", "economía de la cultura", "industrias culturales", "industrias creativas", "economía creativa" en su historicidad y las relaciones existentes entre ellos. En un segundo momento trata de analizar los números de las inversiones de las políticas culturales, pasando los presupuestos del Programa Monumenta y Prodetur. El estudio de caso de turismo comunitario de la isla Mém de Sá, en el municipio de Itaporanga da Ajuda en Sergipe, termina la aplicación del corpus teórico a la experiencia práctica de un modelo de turismo capaz de comprometerse profundamente con la creatividad económica de la cultura. La metodología se caracteriza como cualitativa y cuantitativa en análisis comparativo bibliográfico y estadístico, incluyendo aún un trabajo de campo. La visión romántica de la cultura que mantiene la gente conectado a su tierra, que está solidificado en la transmisión familiar sin la percepción de una rentabilidad financiera se ha desfragmentado frente a los efectos de la globalización con seductoras ofertas de ganancia económica. La economía, por lo tanto, se hace emblemática para repensar esta imagen del turismo. Palabras clave: economía de la cultura; patrimonio cultural; Turismo cultural.

\section{Introdução}

Nos últimos dez anos, termos como "políticas públicas", "políticas culturais", "economia da cultura", "indústrias culturais", "indústrias criativas", "economia criativa" têm adentrado o universo de intelectuais, profissionais $\mathrm{e}$ comunidades produtoras de cultura. Embora a maioria desses conceitos já possua uma longa trajetória de debates e aplicação prática no exterior, no Brasil chegam tardiamente, mas impulsionam teorias e metodologias aliando programas de salvaguarda do patrimônio cultural ao desenvolvimento do turismo cultural no país.

No contexto do dinamismo da cultura, da ressignificação das teorias, sistematizar a ontologia desse processo oferece a possibilidade de aprofundar ainda mais o diálogo em torno do empoderamento da cultura no campo da economia.

$\mathrm{O}$ encontro teórico oficial entre turismo e patrimônio cultural data do final da década de 1960 e meados dos anos de 1970, quando os debates em torno da preservação e da revitalização dos sítios históricos incluíram preocupações que advinham de anos anteriores com as Normas de Quito (1967) ${ }^{1}$ e a Resolução de São Domingos $(1974)^{2}$.

A Carta Patrimonial de 1976, elaborada durante o "Seminário Internacional de Turismo",

1 Ressaltando o potencial dos monumentos como equipamentos turísticos, chamando a atenção para a necessidade de planejamento, infraestrutura de acesso e impactos ambientais.

2 Ressaltando o turismo como um meio de preservação dos monumentos. 
realizado pelo International Council on Monuments and Sites (ICOMOS) em Bruxelas (Bélgica) definiu o Turismo Cultural como:

Aquela forma de turismo que tem por objetivo, entre outros fins, o conhecimento de monumentos e sítios históricos. Exerce um efeito realmente positivo sobre estes tanto quanto contribui - para satisfazer seus próprios fins - a sua manutenção e proteção. Esta forma de turismo justifica, de fato, os esforços que tal manutenção e proteção exigem da comunidade humana, devido aos benefícios sócioculturais e econômicos que comporta para toda a população implicada (ICOMOS, 1976, p.2).

O dinamismo da cultura também ressignificou o turismo em sua interação com o patrimônio cultural na XII Assembleia Geral do ICOMOS, reunida no México em outubro de 1999, substituindo a Carta de Turismo Cultural de 1976 pela Carta Internacional sobre o Turismo Cultural onde se afirma que:

O turismo doméstico e o turismo internacional continuam a estar entre os veículos mais importantes das trocas culturais, proporcionando uma experiência pessoal, não só sobre aquilo que sobreviveu do passado, mas também sobre a vida de outras sociedades contemporâneas. São cada vez mais apreciados como uma força positiva para a conservação natural e cultural. O turismo pode captar as características econômicas do patrimônio e dedicá-las à conservação, gerando fundos, educando a comunidade e influenciando a política. É uma parte essencial de muitas economias nacionais e regionais, e pode ser um importante fator no desenvolvimento, quando administrado adequadamente (Anexo II. Carta Internacional sobre Turismo Cultural apud COSTA, 2014, p.202-203).

Essa relação entre turismo, patrimônio cultural e economia é abordada nesse artigo, que tem como objetivo geral apresentar os conceitos em suas definições, historicidade e relacionamentos existentes entre eles. Como objetivos específicos, analisar os números dos investimentos das políticas culturais, a partir dos dados do Tesouro Nacional entre 2002 e 2016, num exercício de compreensão comparativa entre algumas capitais, para chegar ao estado de Sergipe, perpassando os orçamentos do Programa Monumenta e do Prodetur entre 2007 e 2012. O corpus teórico e metodológico relacionado na primeira parte é então aplicado ao estudo de caso do Turismo de Base Comunitária da Ilha Mem de Sá, no município sergipano de Itaporanga da Ajuda.

Fontes como documentos produzidos pelo Tesouro Nacional, Ministério do Turismo (MTur), Ministério da Cultura, Ministério do Planejamento, Instituto do Patrimônio Artístico e Histórico Nacional (IPHAN), dentre outras, foram pesquisadas.

Tendo essas premissas em voga, a metodologia para a elaboração desse trabalho caracteriza-se como quantitativa, a partir da seleção de referencial teórico norteador e de dados estatísticos das fontes, cotejados com uma literatura pertinente à sua análise de conteúdo e do trabalho de campo realizado na Ilha Mem de Sá que envereda por uma etnografia de percurso.

O surgimento de Observatórios da Cultura, a exemplo de São Paulo, Rio de Janeiro e de Porto Alegre, trouxe um olhar relacional entre a Economia da Cultura e o Turismo em suas convergências e dissenções. Por isso, justificase a produção dessa reflexão sobre Sergipe na ampliação do debate para além do eixo centro-sul, pensando-se as realidades locais na manutenção da memória e das tradições comunitárias como um viés de empoderamento social.

\section{Descortinando a teoria}

A virada dos anos 2000 trouxe discussões teóricas, a partir de vivências práticas do campo cultural, as quais têm enriquecido consideravelmente as dinâmicas da participação social na reivindicação de políticas públicas capazes de elevar o protagonismo dos setores produtivos, dando-lhes voz, vez e empoderamento no mercado e no Estado. Os movimentos por uma democracia mais holística e participativa em que os processos decisórios não se restrinjam ao legislativo e executivo têm marcado a tônica dos novos tempos.

As demandas por uma vida com qualidade no século XXI envolvem desde as questões socioambientais (reciclagem de lixo e resíduos; controle e eliminação da poluição do ar, de rios e mares; combate às queimadas e à derrubada 
de florestas; fim da utilização de agrotóxicos), sociourbanas (eficiência e alternativas na mobilidade; acessibilidade em todos os espaços; construção coletiva de planos diretores municipais; educação e internacionalização); socioeconômicas (empregabilidade; empreendedorismo; aplicação eficaz dos impostos) e socioculturais (proteção e visibilidade; valorização e manutenção; rede solidária e rentabilidade).

A tecnologia inovadora como modelo integrador de vida capaz de gerar o desenvolvimento econômico, o bem-estar, a colaboração, a resiliência, a eficiência, a sustentabilidade e a transparência coaduna-se com os usos do conceito de "cidades inteligentes" 3 em seu rol de expectativas (Coallier, 2016, p.18) e também desponta nos debates contemporâneos sobre planejamento urbano.

Ao se tratar especificamente da questão da rentabilidade advinda da cultura, adentra-se em uma seara de complexidades, uma vez que as comunidades tradicionais têm visto cada vez mais seus jovens, buscando outros afazeres que não a continuidade do ofício de seus pais e avôs para obterem melhor remuneração.

$\mathrm{Na}$ economia de mercado são as forças de oferta e demanda que determinam o preço e a quantidade dos bens e serviços negociados. Grosso modo, busca-se uma relação onde o excedente do produtor (a quantia recebida pelo vendedor de um bem menos seus custos de produção) e o excedente do consumidor (disposição de pagar por um bem menos a quantia do que efetivamente pagam por ele) alcancem a eficiência por meio do equilíbrio (Mankiw, 2013, p.135-151).

Quando se utilizam os saberes da economia a favor da cultura, tomando um caminho distinto da antropologia (valor simbólico), mas alocando seu instrumental teórico e metodológico sobre excedente, valor de produção, eficiência e equilíbrio de mercado, consumo de bem-estar, dentre outros, para segmentos de produção cultural, que podem ter algum impacto no mercado, gerarem sua rentabilidade, lucratividade e sustentabilidade (valor monetário), adentra-se na Economia da Cultura (Reis, 2012). Assim,

3 Grosso modo, o conceito de Smart City proposto por Coallier (2016, p.29) entende como "um espaço urbano onde um sistema intensivo de Tecnologia da Informação (TI) interliga os serviços fazendo-os funcionar de modo "inteligente"”.
[...] a economia da cultura oferece todo o aprendizado e o instrumental da lógica e das relações econômicas da visão de fluxos e trocas; das relações entre criação, produção, distribuição e demanda; das diferenças entre valor e preço; do reconhecimento do capital humano; dos mecanismos mais variados de incentivos, subsídios, fomento, intervenção e regulação; e de muito mais - em favor da política pública não só de cultura, como de desenvolvimento (Reis, 2009, p.25).

Durante muito tempo olhou-se para a cultura, principalmente aquelas que emanam do viés da tradicionalidade das comunidades (o artesanato da renda filé $[\mathrm{AL}]$ ou das panelas de Goiabeiras [ES], as danças e folguedos de Laranjeiras [SE], os gêneros alimentícios como o queijo do Serro [MG] ou a cajuína [PI]), como elementos identitários de raiz que não cabiam "precificação", pois isso retiraria deles sua singularidade, resistência e mesmo "cultura identitária" para inseri-los num capitalismo "desfigurador", competitivo e homogeneizador.

O cerne do problema dessa concepção reducionista está na demora dos pesquisadores brasileiros em abordarem o tema sob outro enfoque, pois embora a economia da cultura seja reconhecida como disciplina no campo da Economia desde a década de 1960, no Brasil o termo chegou bem tardiamente, em 2003 (Reis, 2012).

A economia da cultura lida essencialmente com "os bens, serviços e manifestações culturais que entram (ou poderiam entrar) em um fluxo completo de produção, distribuição e consumo" (Reis, 2009, p.28).

O pleno desenvolvimento da Economia da Cultura requer a idealização, o planejamento e a execução de Políticas Culturais ${ }^{4}$ que possam 4 As políticas culturais integram uma parte de um conjunto maior denominado de "políticas públicas", compreendidas por Peters (1986) como "a soma das atividades dos governos, que agem diretamente ou através de delegação, e que influenciam a vida dos cidadãos". $\mathrm{Na}$ atualidade, várias definições têm caminhado para um sentido mais holístico e multicêntrico, em que governos e sociedade civil (organizações, universidades, entidades privadas, associações comunitárias, categorias profissionais) devem atuar juntos na formulação e na decisão por soluções que atendam às necessidades coletivas nas territorialidades. O foco recai sobre a colaboração e os limites do próprio governo (Souza, 2006, p.24-25). 
viabilizar o incremento da produção cultural. De acordo com o pesquisador Nestor Canclini (2001, p.65), as políticas culturais compreendem um:

...conjunto de intervenções realizadas pelo Estado, instituições civis e grupos comunitários organizados a fim de orientar o desenvolvimento simbólico, satisfazer as necessidades culturais da população e obter consenso para um tipo de ordem ou de transformação social.

Inserindo a cultura no plano da economia, José Teixeira Coelho Neto (1997, p.292) ressalta que cabe aos agentes "promover a produção, a distribuição e o uso da cultura, a preservação e divulgação do patrimônio histórico e o ordenamento do aparelho burocrático por elas responsável”. Ao que Alexandre Barbalho (2015, p.30) complementa, chamando a atenção para o fato de que "os programas de intervenções e os conjuntos de iniciativas não se dão de forma consensual, mas resultam de uma relação de forças culturais e políticas", ou seja, existem tensões, conflitos e disputas pelo poder no interior das instituições, dos próprios produtores de cultura e entre ambos.

Há pelo menos 12 anos o país viu a emergência de políticas culturais abrangendo realizações como o Plano Nacional de Cultura (e na sua esteira os Planos Municipais e Estaduais de Cultura), o Sistema Nacional de Cultura, a Reforma da Lei Rouanet, a PEC 150 e o Vale-Cultura, o Sistema de Museus (Nacional, Estaduais e Municipais), o Plano Nacional de Turismo, o Prodetur, dentre outros.

As iniciativas para a salvaguarda das tradições e da cultura imaterial alocando fomentos para sua manutenção e potencialização levou o Ministério da Cultura (MinC) à criação de várias formas de concessão de incentivos que, distante da ideia de "caridade", representassem a vontade de participação na elaboração de projetos e concorrências, assim:

[...] os editais, prêmios e programas elaborados pela Secretaria da Identidade e da Diversidade Cultural, têm nas culturas tradicionais e populares $\mathrm{o}$ seu foco, bem como a demanda do programa Cultura Viva, que estabelece com competência e eficácia a rede dos Pontos de Cultura, na perspectiva da gestão territorial, pelo país inteiro, como sempre, com editais e prêmios (Rocha, 2009, p.42).

Com o foco na diversidade cultural, a obtenção de recursos financeiros via canais institucionais públicos, e às vezes privados (como é o caso de bancos que investem em projetos culturais, a exemplo do edital Itaú Cultural; das ações do Centro Cultural Banco do Brasil, prêmios Santander de Inovação; Prêmio Professor Samuel Benchimol e Banco da Amazônia de Empreendedorismo Consciente), traduz a transparência das contas com lucros, despesas e investimentos, principalmente de órgãos públicos. Referenda uma espécie de "retorno social" muito exigido pela sociedade nos últimos tempos.

Assim, os produtores de cultura (individuais e coletivos) são selecionados e agraciados pela habilidade demonstrada na concorrência aos editais, quebrando os grilhões de políticas de doações paternalistas promotoras de subserviência em troca de votos. Todavia, frente às realidades desiguais no país, em termos de instrução formal, esse passo precisa ser acompanhado de ações de instrumentalização dos grupos produtores de cultura no sentido de facilitar o acesso à informação de abertura, prazos, documentos necessários, prestação de contas, preenchimento dos formulários, planilhas, dossiês e projetos relacionados aos editais. Oficinas de atualização de conhecimento junto às comunidades, organizadas por secretarias de cultura e universidades públicas, dentre outras organizações, têm sido um apoio fundamental para o processo emancipatório de coronelismos ainda vigentes no século XXI.

Nesse sentido, ainda na linha da ontologia da discussão apresentada até aqui, torna-se pertinente trazer à baila o conceito de economia criativa existente no mundo desde meados da década de 1990, com uma concepção de ampliação da economia da cultura, advindo das discussões em torno das "indústrias criativas" (Reis, 2012). Zallo (1988, p.26), inicialmente chamando-as de "indústrias culturais", as define como um:

... conjunto de ramos, segmentos e atividades auxiliares industriais produtoras e distribuidoras de mercadorias com conteúdos simbólicos, concebidas por um trabalho criativo, organizadas por um capital que se valoriza e destinadas finalmente aos mercados de consumo, com uma finalidade de reprodução ideológica e social. 
Integrariam essas indústrias os complexos editoriais, fonográficos, audiovisuais e aqueles domínios transversais, auxiliares e relacionados, como a propaganda, suportes, insumos, telecomunicações e informática (Getino, 2003).

As reflexões mais atualizadas sobre políticas culturais caminham no sentido de "considerar os aspectos materiais e simbólicos da cultura, entendendo tanto as implicações econômicas quanto as peculiaridades que transcendem uma lógica meramente mercantil das mercadorias" (Bayardo, 2013, p.10). Tomam por base os debates no âmbito da UNESCO (2001 e 2005), afirmando que:

... os bens e serviços culturais não são mercadorias como outras quaisquer, mas sim mercadorias que comunicam ideias, portam conteúdos, veiculam valores, portam sentidos, que fazem a formação dos sujeitos, os modos de sociabilidade e as formas de entender a natureza, o mundo, as relações com os outros (apud Bayardo, 2013, p.10).

Nesse sentido é ressaltado o potencial de "criatividade da cultura" e entende-se por criatividade "a capacidade não só de criar o novo, mas de reinventar, diluir paradigmas tradicionais, unir pontos aparentemente desconexos e, com isso, equacionar soluções para novos e velhos problemas" (Reis, 2008, p.15).

No plano econômico, cresceu a retórica de que a criatividade da cultura e consequentemente as "indústrias criativas", aliando as dimensões simbólicas à troca de conhecimentos, permitem a geração de riquezas, renda e empregos via empreendedorismo, inovação e sustentabilidade. Pois:

Bens e serviços culturais e criativos estão enraizados em nossas vidas e são consumidos sem necessariamente ser intermediados pelo mercado. A questão crucial é que a sustentabilidade da produção cultural depende da capacitação de talentos (o que implica a possibilidade de o produtor cultural sobreviver de sua produção ou ter tempo ocioso para se dedicar a ela de maneira diletante); que essa produção ou tradição circule (garantindo assim a renovação da diversidade cultural); e que o acesso a essa produção seja garantido (em especial dos jovens), em um jogo de forças da cultura de massas acirrado pela globalização (Reis, 2008, p.15).

Historicamente o conceito de "economia criativa" emana da ideia de "indústria criativa" inspirado no projeto Creative Nation, da Austrália, de 1994. Em 1997, quando se concretizou a eleição de Tony Blair como primeiro ministro do Reino Unido, iniciou-se uma revisão econômica buscando recuperar a competitividade do Reino Unido bebendo da fonte do que seria diferenciado no país (Reis, 2012). Como resultado:

... a economia criativa tem suscitado discussões e estudos em áreas não puramente ligadas a uma política industrial ou econômica, mas tão vastas como atinentes à revisão do sistema educacional (questionando a adequação do perfil dos profissionais de hoje e anunciando a emergência de novas profissões), a novas propostas de requalificação urbana (gerando projetos de clusters criativos e reposicionamento das chamadas cidades criativas), à valoração do intangível cultural por parte de instituições financeiras (clamando por modelos de mensuração inspirados nos setores de patentes e marcas), a um reposicionamento do papel da cultura na estratégia socioeconômica (lidando paralelamente com conteúdos simbólicos e econômicos) e até mesmo à revisão da estrutura econômica, de cadeias setoriais para redes de valor, incluindo novos modelos de negócio (graças às novas tecnologias e à emergência de criações colaborativas) (Reis, 2008, p.18-19).

Talvez um dos reflexos mais presente nesse turbilhão de conceitos propostos, apreendidos e em contínua reformulação por intelectuais e agentes culturais em sua dinâmica teórica e prática, seja a difusão de mapeamentos das cadeias produtivas comparando seus gastos com o crescimento econômico gerado por elas em outros setores, comprovando que "gasto em cultura é investimento".

Reafirma-se assim a abrangência e o poder da cultura em gerar lucratividade para além de seu circuito, a exemplo de como o investimento 
inteligente em um determinado museu de uma localidade (tendo por base um planejamento que envolva desde as funções básicas da Museologia - política de aquisição de acervos, documentação, conservação preventiva, comunicação e montagem de exposições, uso de tecnologia, projetos educativos e avaliação de público - e também sua relação com o turismo) está diretamente vinculado à mobilidade urbana (os gastos do público visitante no transporte público e nos estacionamentos privados) e ao setor gastronômico (os gastos com alimentação após a visitação).

Esses levantamentos relacionais envolvem teatro, cinema, parques, shows e uma série de outras atividades culturais, e embora ainda sejam escassos, têm ressoado como um clamor por parte daqueles que atuam diretamente no setor cultural. Nesse sentido os estudos de impacto que buscam mapear a produção, a distribuição e o consumo, tendo por base o investimento e o retorno, geram efeitos multiplicadores e conferem "poder de negociação" aos produtores de cultura.

\section{Observatórios Culturais e transparência pública nos investimentos}

Um dos passos iniciais no sentido da transparência pública foi dado pelo Observatório da Cultura da Secretaria Municipal de Cultura de Porto Alegre ao criar um blog (http:// culturadesenvolvimentopoa.blogspot.com. br/2017/05/patrimonio-cultural-quanto-gastamas.html) em que, a partir de dados do Tesouro Nacional, divulgou um quadro dos gastos com a cultura realizados pelas capitais do país entre 2002 e 2016.

Assim, vinte e sete capitais são escrutinadas em seus números, abrangendo a demografia da localidade, a despesa total, o investimento em cultura, o percentual e o valor real por habitantes. Posteriormente, o acesso aos portais de transparência para descortinar os valores arrecadados com impostos municipais, podendo ser cruzado com os dados apresentados na tabela para se verificar o quanto de retorno cultural às populações estão recebendo.

$\mathrm{Na}$ Tabela 1, aparece em destaque amarelo a capital que investiu menos em cultura ( $\mathrm{R} \$ 82.608,00)$, perfazendo um percentual de 0,05 configurado em um gasto de $\mathrm{R} \$ 0,24$ por habitante em 2002. No mesmo quadro é possível comparar os investimentos realizados entre capitais de todas as regiões, ressaltando-se que o maior gasto foi feito em Boa Vista, considerando-se a demografia daquele espaço, com um percentual de 3,42 configurando $\mathrm{R} \$ 33,45$ por habitante.

Observa-se que São Luís manteve um investimento $(1,66 \%)$ maior em cultura do que o Rio de Janeiro (1,33\%) e São Paulo (1,38\%). E ainda Natal (0,40\%), Salvador (0,44\%), João

Tabela 1: Comparativo Capitais 2002

\begin{tabular}{|c|c|c|c|c|c|c|c|c|c|c|}
\hline & A & B & c & D & E & $\mathrm{F}$ & G & $\mathrm{H}$ & 1 & J \\
\hline 1 & MUNICIPIO & População & Despesa total & Cultura & & & & $\%$ cultura & & RS $\rho / h a b$. \\
\hline 2 & ARACAJU & 473.991 & 297.006 .898 .77 & 4.505 .484 .98 & & & & $1.52 \%$ & & $\mathrm{R} \$ \quad 9.51$ \\
\hline 3 & BELEM & 1.322 .683 & $592.222 .551,66$ & $6.413 .347,80$ & & & & $1,08 \%$ & & $\mathrm{R} \$ \quad 4,85$ \\
\hline 4 & BELO HORIZONTE & 2.284 .468 & $1.967 .154 .661,75$ & $17.268 .749,26$ & & & & $0,88 \%$ & & $\mathrm{R} \$ 7,56$ \\
\hline 5 & BOA VISTA & 214.541 & $209.623 .431,47$ & $7.176 .961,01$ & & & & $3,42 \%$ & & $\mathrm{R} \$ 33,45$ \\
\hline 6 & CAMPO GRANDE & 692.549 & $553.777 .412,38$ & $2.919 .502,62$ & & & & $0,53 \%$ & & $\mathrm{R} \$ \quad 4,22$ \\
\hline 7 & CUIABA & 500.288 & 362.753 .054 .22 & 532.534 .06 & & & & $0,15 \%$ & & $\mathrm{R} \$ 1.06$ \\
\hline 8 & CURITIBA & 1.644 .600 & $1.778 .903 .495,98$ & $20.224 .011,11$ & & & & $1,14 \%$ & & $\mathrm{R} \$ 12,30$ \\
\hline 8 & FLORIANOPOLIS & 360.601 & $305.723 .445,56$ & $3.335 .029,00$ & & & & $1,09 \%$ & & $\mathrm{R} \$ \quad 9,25$ \\
\hline 10 & FORTALEZA & 2.219 .837 & $1.037 .858 .923,72$ & $4.723 .715,36$ & & & & $0,46 \%$ & & $\mathrm{R} \$ \quad 2,13$ \\
\hline 11 & GOIANIA & 1.129 .274 & 889.525 .024 .13 & 1.453 .827 .74 & & & & $0.16 \%$ & & $\mathrm{R} \$ 1.29$ \\
\hline 12 & JOAO PESSOA & 619.049 & $266.701 .191,84$ & $1.603 .769,88$ & & & & $0,60 \%$ & & $\mathrm{R} \$ 2,59$ \\
\hline 13 & MACAPA & 306.583 & 143.145 .501 .59 & 147.613 .29 & & & & $0,10 \%$ & & $\mathrm{R} \$ \quad 0,48$ \\
\hline 14 & MACEIO & 833.261 & $390.702 .551,11$ & 4.196.292,74 & & & & $1,07 \%$ & & $\mathrm{R} \$ 5,04$ \\
\hline 15 & MANAUS & 1.488 .805 & 768.519 .813 .76 & $7.215 .369,82$ & & & & $0,94 \%$ & & $\mathrm{R} \$ 4.85$ \\
\hline 16 & NATAL & 734.505 & $385.341 .001,17$ & 1.559.171,24 & & & & $0,40 \%$ & & $\mathrm{R} \$ \quad 2.12$ \\
\hline 17 & PALMAS & 161.137 & $159.030 .551,17$ & $2.534 .341,63$ & & & & $1,59 \%$ & & $\mathrm{R} \$ 15,73$ \\
\hline 18 & PORTO ALEGRE & 1.383 .454 & $1.620 .740 .955,82$ & 17.756 .073 .78 & & & & $1,10 \%$ & & $\mathrm{R} \$ 12,83$ \\
\hline 18 & PORTO VELHO & 347.844 & $170.267 .837,37$ & $82.608,00$ & & & & $0,05 \%$ & & $\begin{array}{ll}\mathrm{R} & 0.24\end{array}$ \\
\hline 20 & RECIFE & 1.449 .135 & 976.175 .221 .00 & 12.949 .122 .00 & & & & $1,33 \%$ & & $\mathrm{R} \$ 8.94$ \\
\hline 21 & RIO BRANCO & 267.740 & $169.081 .055,56$ & $606.235,58$ & & & & $0,36 \%$ & & $\mathrm{R} \$ \quad 2,26$ \\
\hline 22 & RIO DE JANEIRO & 5.937 .253 & $6.415,050,701.73$ & 85.006 .237 .35 & & & & $133 \%$ & & $\mathrm{R} \$ 14,32$ \\
\hline 23 & SALVADOR & 2.520 .504 & 1.072 .850 .990 .03 & $4.677 .579,66$ & & & & $0,44 \%$ & & $\mathrm{R} \$ \quad 1,86$ \\
\hline 24 & SAO LUIS & 906.567 & 553.391 .196 .74 & 9.205 .802 .47 & & & & $1,66 \%$ & & $\mathrm{R} \$ 10,15$ \\
\hline 25 & SAO PAULO & 10.600 .060 & $9.690 .336 .280,88$ & 133.925 .783 .42 & & & & $1,38 \%$ & & $\mathrm{R} \$ 12.63$ \\
\hline 26 & TERESINA & 740.016 & $390.150 .536,00$ & $3.477 .955,00$ & & & & $0,89 \%$ & & $\mathrm{R} \$ \quad 4,70$ \\
\hline 27 & VITORIA & 299.357 & 405.777 .299 .27 & 6.102 .181 .65 & & & & $1.50 \%$ & & $R \$ 20.38$ \\
\hline
\end{tabular}

Fonte: Dados do Tesouro Nacional disponibilizados pelo Observatório da Cultura. Secretaria Municipal de Cultura de Porto Alegre, 2017. 
Tabela 2: Comparativo Capitais 2015

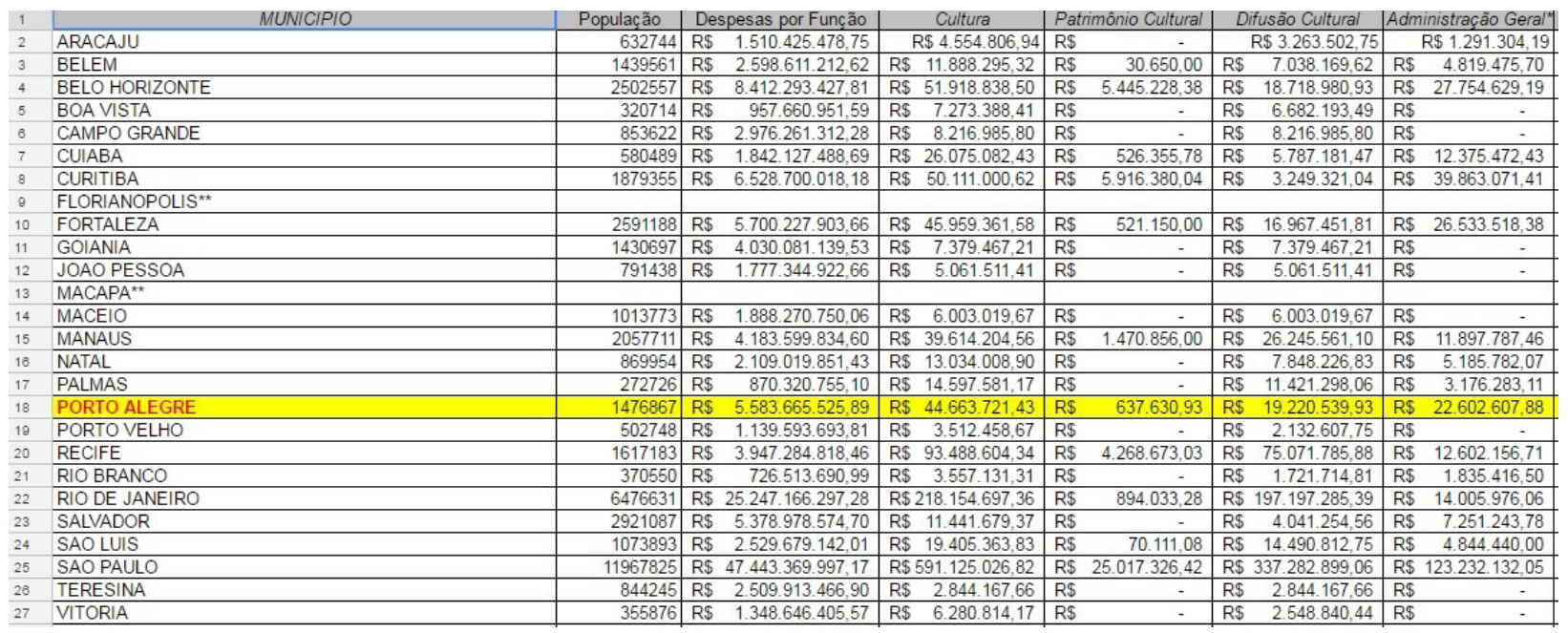

Fonte: Dados do Tesouro Nacional disponibilizados pelo Observatório da Cultura. Secretaria Municipal de Cultura de Porto Alegre, 2017.

Pessoa $(0,44 \%)$ e Fortaleza $(0,46 \%)$ apresentaram gastos pífios em comparação com Aracaju (1,52\%) e Palmas (1,59\%).

A posse desses dados pela população, dentro dos princípios de circulação do conhecimento, as torna mais capazes de fazer valer seu direito cidadão junto às instâncias governamentais para que seu "direito à cultura" embasado no seu "dever de pagadores de impostos" seja respeitado e ampliado.

A Tabela 2 traz a realidade dos gastos efetuados em 2012, sendo destacado o gasto de Porto Alegre com o investimento de $\mathrm{R} \$ 44.663 .721,43 \mathrm{em}$ Cultura, sendo $\mathrm{R} \$$ 637.630,93 em Patrimônio Cultural e R \$ 19.220.539,93 em difusão cultural. Houve um gasto percentual de 0,88 em cultura e sendo investidos $\mathrm{R} \$ 30,21$ por habitante. Houve um aumento significativo nesses 13 anos, uma vez que, como pode ser verificado na Tabela 1, a mesma capital investiu $\mathrm{R} \$ 17.756 .073,78$, configurando $1,10 \%$ em cultura e $\mathrm{R} \$ 12,83 \%$ por habitante.

E até mesmo Porto Velho, ao longo desses anos, apresentou um aumento nos seus gastos, perfazendo $0,53 \%$ com cultura $(\mathrm{R} \$ 3.512 .458,67)$, sendo investidos $\mathrm{R} \$ 12,04$ por habitante.

A segunda tabela trouxe dados mais detalhados, especificando os gastos em patrimônio cultural, difusão cultural, administração geral e outras despesas na função cultura.

A preocupação com o patrimônio histórico, artístico e arqueológico, capitaneada por programas como o Monumenta ${ }^{5}$ e o $\mathrm{PAC}^{6}$, além da legislação competente $^{7}$, trouxe dados que permitiram a elaboração de um gráfico (Figura 1) sobre o orçamento empenhado entre 2004 e 2016 pelas capitais brasileiras. O maior susto ficou por conta da realidade de Salvador, que aparece (ao lado de Maceió e Teresina) com investimento em $0 \%$ nessa área.

A média das capitais ficou um pouco abaixo de $0,05 \%$. Florianópolis foi a capital que apresentou o maior investimento (acima de 0,20\%), seguida por Recife e Belém (mais de 0,10\%). Uma das mais expressivas capitais nacionais, o Rio de Janeiro, não chegou nem perto da média, orbitando entre $0,02 \%$.

Essas informações são de suma importância para a área turística, pois os planejamentos em

5 Concebido no final da década de 1990, o Programa Monumenta viabilizou a recuperação de 300 edifícios, beneficiando mais de mil moradores de centros históricos. Buscou-se a realização de "investimentos em restauração, em recuperação de espaços públicos e em promoção de atividades que induzam à apropriação e à vitalidade econômica" (Machado, 2009, p.14).

6 O Programa de Aceleração das Cidades (PAC) foi criado em 2007 para executar grandes obras de infraestrutura social, urbana, logística e energética no país. $\mathrm{O}$ PAC cidades históricas foi lançado em 2013 com 424 ações voltadas para a recuperação, restauro e qualificação de monumentos e de conjuntos urbanos. Para as obras, o governo federal disponibilizou $\mathrm{R} \$ 1,6$ bilhão (Ministério do Planejamento, 2015, p.75-78).

7 A exemplo da Instrução Normativa ${ }^{\circ} 001$, de 25 de março de 2015, que estabelece procedimentos administrativos a serem observados pelo Instituto do Patrimônio Histórico e Artístico Nacional nos processos de licenciamento ambiental dos quais participe. 


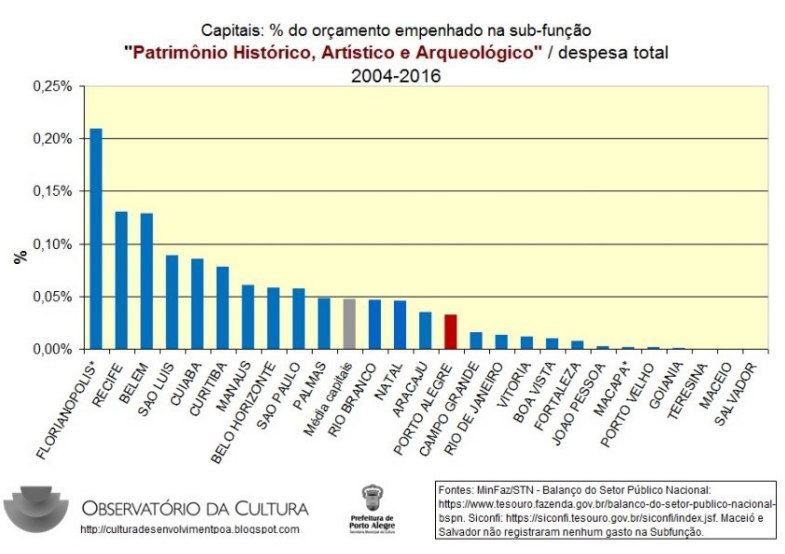

Figura 1: Capitais: \% do orçamento empenhado na subfunção "Patrimônio Histórico, Artístico e Arqueológico"/despesa total (2004-2016)

Fonte: Dados do Tesouro Nacional disponibilizados pelo Observatório da Cultura. Secretaria Municipal de Cultura de Porto Alegre, 2017.

torno da fruição dos atrativos turísticos culturais requer a clareza no compromisso dos governantes quanto aos gastos com o patrimônio cultural.

Patrimônios culturais materiais degradados, além de não despertarem o interesse do turista, oferecem tanto o risco àqueles, quanto à própria população residente em seu entorno.

Essa situação também evidencia uma atitude de desrespeito dos poderes públicos com as normativas, as resoluções e os acordos firmados nacional e internacionalmente para a salvaguarda do patrimônio cultural nas Cartas Patrimoniais, desde 1930, no âmbito da UNESCO, ICOM, ICOMOS, IPHAN, dentre outros.

Ao acompanhar o gráfico que traz a curva das despesas com o patrimônio cultural por habitantes nas capitais brasileiras em comparação com o IPCA ${ }^{8}$, no período de 2004 a 2016, verifica-se que, embora tenha ocorrido uma situação quase contínua de ascendência, sofrendo uma queda apenas em 2012, o ano de 2014 foi o que apresentou o maior índice de investimento com pouco mais

8 O IPCA é o índice oficial do Governo Federal para medição das metas inflacionárias, contratadas com o FMI a partir de julho/99. A partir de janeiro/2012, o IPCA passou a ser calculado com base nos valores de despesa obtidos na Pesquisa de Orçamentos Familiares - POF 2008-2009. A POF é realizada a cada cinco anos pelo IBGE em todo o território brasileiro, o que permite atualizar os pesos (participação relativa do valor da despesa de um item consumido em relação à despesa total) dos produtos e dos serviços nos orçamentos das famílias. Disponível em: http://www.portalbrasil.net/ ipca. htm. Acesso em: 03/06/2017.

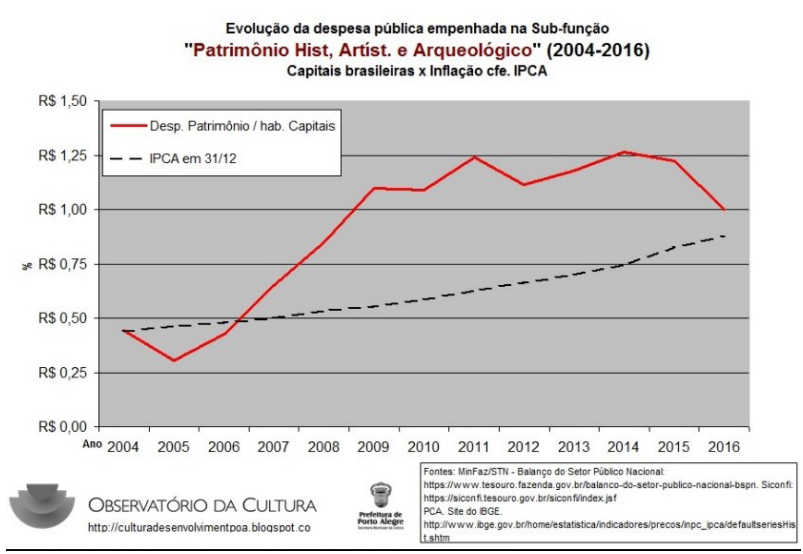

Figura 2: Evolução da despesa pública empenhada na subfunção "Patrimônio Histórico, Artístico e Arqueológico" (2004-2016). Capitais brasileiras x Inflação cfe. IPCA

Fonte: Dados do Tesouro Nacional disponibilizados pelo Observatório da Cultura. Secretaria Municipal de Cultura de Porto Alegre, 2017.

de $\mathrm{R} \$ 1,25$, decaindo consideravelmente para $\mathrm{R} \$ 1,00$ a partir de 2016. Já o IPCA apresenta taxa de crescimento contínua, revelando disposição para consumo.

No menor estado brasileiro, Sergipe, a capital Aracaju apresentou um gasto com cultura em 2002 na ordem de $\mathrm{R} \$ 4.505 .484,98$, perfazendo $1,52 \%$ de seu investimento na área atribuído a $\mathrm{R} \$ 9,51$ por habitante (tabela 1). Já em 2015, embora os gastos tenham demonstrado um acréscimo em valores monetários ( $\mathrm{R} \$ 4.554 .806,94)$ com investimento de $\mathrm{R} \$ 12,84$ por habitante, revelaram um decréscimo percentual para $0,53 \%$ (Tabela 2).

No comparativo geral entre as capitais no período de 2002 a 2016, Aracaju aparece no $13^{\circ}$ lugar (Figura 1), um pouco abaixo da média nacional de investimentos em cultura, com aproximadamente $0,04 \%$ de seu orçamento voltado para o patrimônio cultural. Ficou à frente de capitais expressivas como Rio de Janeiro, Fortaleza, João Pessoa e Salvador.

Uma parte desses dados talvez possa ser explicada pelo fato de que, no auge do governo presidencial de Luis Inácio Lula da Silva do Partido dos Trabalhadores, tanto a prefeitura de Aracaju quanto o governo do estado tiveram gestores do PT (caso de Marcelo Deda) ou aliados, facilitando a liberação de verbas. Ressalta-se ainda o trabalho efetivo do gestor cultural Irineu Fontes, que durante esse período exerceu primeiro o cargo de secretário de Cultura da Prefeitura de Laranjeiras e depois trabalhou diretamente na 
Secretaria de Cultura do Governo do Estado. Fontes impulsionou a realização de Conferências Municipais e Estadual de Cultura, elaborando o Plano Municipal de Cultura (Laranjeiras) e foram retomadas as reuniões do Conselho Estadual de Cultura (dentre elas o trabalho em rede com as demais capitais do Nordeste e as discussões sobre o tombamento das edificações no centro histórico de Aracaju). O crescimento menos expressivo em 2015 remonta aos problemas políticos no país e a crise financeira ocorrida em vários estados e capitais, dentre elas, Aracaju.

Ressalta-se ainda a atuação do Programa Monumenta em duas cidades importantes para o turismo em Sergipe: São Cristóvão e Laranjeiras. $\mathrm{Na}$ primeira cidade (cujo sítio urbano foi fundado em 1575 e o tombamento ocorreu em 1939), foram realizadas obras em monumentos históricos, como o Sobrado da Antiga Ouvidoria, o Museu Histórico do Estado de Sergipe, o Lar Imaculada Conceição, o Convento e Igreja de Santa Cruz, a Igreja de Nossa Senhora do Rosário dos Homens Pretos e a Capela dos Capuchinhos, além de espaços públicos como as Praças da Bandeira, São Francisco e Senhor dos Passos (Largo do Carmo), as Ladeiras de Epaminondas (Beco da Poesia), o Porto da Banca e o Açougue, o Largo do Rosário e o Beco do Amparo. Também foram patrocinados os projetos do Restaurante do Japonês e a Casa da Queijada. Foram disponibilizados recursos de $\mathrm{R} \$ 4,9$ milhões, sendo $\mathrm{R} \$ 1,2$ milhões na recuperação de imóveis privados (Diogo, 2009, p.124).

Já em Laranjeiras (com fundação do sítio urbano também em 1575 e tombamento em 1996) foram realizadas obras em monumentos históricos como a Igreja Matriz do Sagrado Coração de Jesus e trapiche carpintaria da prefeitura, fomentando a criação do novo campus da Universidade Federal do Sergipe (UFS) no antigo quarteirão dos trapiches, casarão de oitão da praça da República, casarão dos Rollemberg e sobrado ao lado. Também foram realizadas obras nos espaços públicos das Praças do Trapiche Santo Antônio, da República e Samuel de Oliveira, Av. Municipal e praça do Sagrado Coração de Jesus, no Calçadão Getúlio Vargas e na praça Cel. José de Faro. Houve o patrocínio de projeto de Educação Patrimonial junto às escolas da comunidade. O custo foi orçado em 6,9 milhões com gasto de $\mathrm{R} \$ 566$ mil na recuperação de imóveis privados (Diogo, 2009, p.130).

A importância desses investimentos no patrimônio cultural sergipano de cidades históricas reverbera principalmente em benefícios nas contas dos empreendimentos turísticos situados em Aracaju, uma vez que a concentração hoteleira e gastronômica na capital oferece a Laranjeiras e São Cristóvão a infraestrutura turística que as mesmas ainda não possuem. A capital recebeu ainda mais de $\mathrm{R} \$ 150$ milhões do Ministério do Turismo entre 2004 e 2011 (MTur, 2012).

Ressalta-se ainda a participação do ministério no investimento de quase $\mathrm{R} \$ 800$ milhões em obras de infraestrutura turísticas nos últimos dez anos. Os recursos financiaram obras importantes como as pontes jornalista Joel Silveira (interligando Aracaju ao litoral Sul do estado) e a Estância/ Indiaroba (eixo rodoviário de ligação entre o Sergipe e a Bahia). As duas obras receberam aporte de mais de $\mathrm{R} \$ 130$ milhões segundo o MTur (2012).

A região de Canindé do São Francisco, que abriga os cânions do rio São Francisco, também foi beneficiada com investimentos financeiros, sendo também direcionados recursos de $\mathrm{R} \$ 7$ milhões para a elaboração de Planos de Desenvolvimento Integrado de Turismo Sustentável (PDITS), qualificação, elaboração de pesquisas e planos de marketing, etc. (MTur, 2012).

\section{Cenários do turismo cultural em Sergipe: o TBC da Ilha Mem de Sá}

No que diz respeito aos PDITS, apoiados pelo MTur em Sergipe, o Polo Costa dos Coqueirais compreende Itaporanga d'Ajuda, ressaltando as potencialidades da Ilha Mem de Sá (Technum Consultoria, 2013, p.122-124).

A comunidade Mem de Sá situa-se numa ilha fluvial no estuário do rio Vazabarris, (demarcada a $11^{\circ} 29^{\prime} 26^{\prime}$ 'S e $\left.06^{\prime} 46^{\prime \prime W}\right)$, localizada a $23 \mathrm{Km}$ da sede do município de Itaporanga D' Ajuda, e $53 \mathrm{Km}$ de Aracaju, capital do estado de Sergipe (Figura 3). A povoação da ilha originou-se de três famílias estabelecidas ao longo do tempo em íntima relação com o meio ambiente caracterizado pelos ecossistemas de restinga e mangue, fazendo da pesca a principal atividade econômica, além dos destaques ao cultivo da mandioca e do aproveitamento do coco (EMBRAPA, 2007).

Desde 2008 o Instituto Federal de Sergipe (IFS) desenvolve ações de inventário e diagnóstico participativo no local sob a supervisão do Grupo de Pesquisa Turismo, Educação e Cultura, vinculado ao curso de Gestão do Turismo. O foco é o cotidiano 


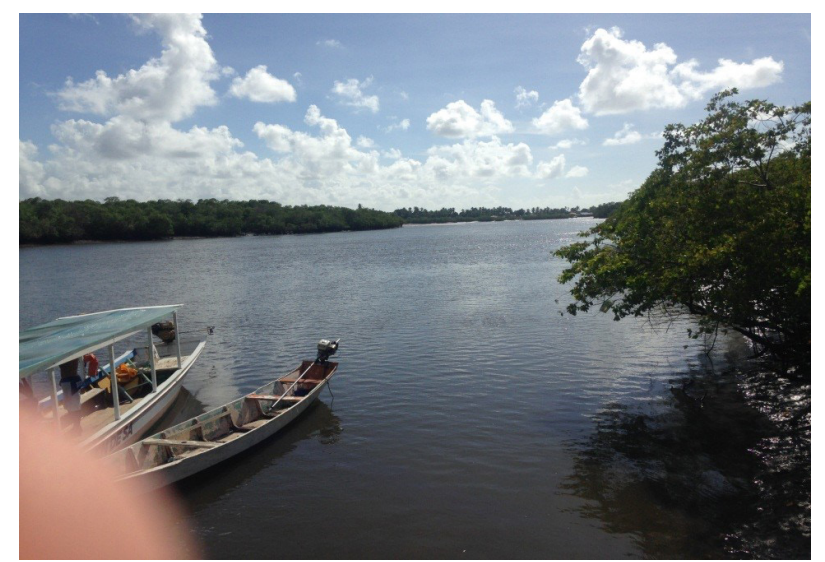

Figura 3: Atravessando o rio para ir à Ilha. Fonte: Foto EPSS, 2017.

dos moradores locais, em grande parte pescadores artesanais, o qual tem sido valorizado e estruturado turisticamente (Technum Consultoria, 2013, p.123)

O Projeto "Re-Conhecer Pedra Bonita" gerou um espaço de diálogo sobre o turismo no município. O Diagnóstico Rural Participativo (DRP) possibilitou aos moradores identificar os potenciais atrativos turísticos da região. A contribuição comunitária permitiu gerar e executar o Roteiro Pedra Bonita (Technum Consultoria, 2013, p.123).

Em fevereiro de 2015 foi lançado o projeto "Aratu, Turismose Base Comunitária", financiado pelo Programa Integração Petrobras Comunidades, visando à implantação de uma cooperativa de turismo e infraestrutura básica receptiva com o objetivo de fortalecer as atividades, os produtos e os serviços ecoturísticos. ${ }^{9}$

Conforme Burgos e Mertens (2015, p.58), o discurso oficial sobre o Turismo de Base Comunitária (TBC) enfatiza a organização e a participação dos atores locais, assumindo um papel ativo no planejamento e na gestão da atividade turística, buscando o bem-estar e a geração de benefícios para seus membros. Sob esse aspecto,

... a gestão participativa é entendida aqui como processo e instrumento dinamizador resultante do engajamento de indivíduos em ações coletivas, onde diferentes atores sociais viabilizam um projeto, procurandoum objetivocomum, mas mantendo as particularidades de seus lineamentos de ação e interesses pessoais (Burgos; Mertens, 2015, p.58).

9 Disponível em: http://www.inclusaosocial.com/aratu-lancamento/. Acesso em: 05/02/2017.
Segundo Bento Cruz, que foi coordenador executivo do Projeto "Ilha dos Aratus", nos últimos anos, o Instituto Federal de Sergipe (IFS) promoveu diversos projetos de pesquisa e extensão na Ilha, e ao longo do processo de interação entre comunidade, pesquisadores e visitantes foi desenvolvida uma ideia sobre o gerenciamento e a operacionalização das atividades turísticas. Cruz, consultor e pesquisador na área de Planejamento Regional e Local com ênfase em Desenvolvimento Comunitário, garantiu que o projeto foi elaborado e seria executado a partir de 2015 , de acordo com as necessidades e as características locais. ${ }^{10}$

O TBC revela-se como uma alternativa ao turismo massificado, com menor densidade de infraestrutura e serviços, valorizando a vinculação aos ambientes naturais e à cultura de cada lugar. Não se trata, apenas, de percorrer rotas exóticas, distintas do turismo de massa. Personifica outro modo de visita e hospitalidade, diferenciado em relação ao turismo massificado, ainda que coincida com um mesmo destino (Bartholo et al., 2009). De acordo com a ONG Projeto Bagagem:

Turismo comunitário é a atividade turística que apresenta gestão coletiva, transparência no uso e na destinação dos recursos, e na qual a principal atração turística é o modo de vida da população local. Nesse tipo de turismo a comunidade é proprietária dos empreendimentos turísticos e há a preocupação em minimizar o impacto ambiental e fortalecer ações de conservação da natureza (Mtur, 2010, p.16).

Além da diversidade do ecossistema e da pesca artesanal, a ilha possui uma herança cultural negra muito forte de onde advém o "samba de coco" - uma dança de roda, cantada em coro e refrão acompanhada de pandeiros, bumbo, ganzás, cuícas e das palmas - caracterizando uma tradição popular nordestina que precisou se reinventar.

O samba de coco da Ilha Mem de Sá, em sua origem há 40 anos, era uma prática cultural que os moradores mantinham nas comemorações do São João, em junho, sem apresentações para o público externo. Era uma brincadeira do povoado que terminava com um banho no poço para "espantar a ressaca”, como atestam os residentes. Com o tempo, a tradição foi se perdendo no cotidiano de trabalho das mulheres e homens da localidade (entrevista informal realizada em 2016).

10 Idem, ibidem. 
Recentemente foi realizado um trabalho na escola local para a revitalização do samba de coco e foi formado o grupo Nova Geração. As senhoras com mais de 60 anos contam orgulhosas como desde meninas "já pulavam dentro de casa" e algumas, além do samba de coco, também aprenderam a dançar o reisado e a quadrilha (entrevista informal realizada em 2016).

O desenvolvimento do TBC na ilha animou a busca pela ancestralidade cultural africana, assim, as apresentações agora também são realizadas em encontros culturais de Sergipe e para pequenos grupos turísticos que visitam o próprio espaço. Por isso, entoando refrãos como "nós somos da ilha pode acreditar" e "samba no terreiro, muie", mais de dez mulheres (jovens e idosas) com vestidos de chita estampados e sandálias de couro dançam em dupla na roda, sincronizando e, ao mesmo tempo, acelerando seus movimentos com fortes batidas de pé no chão de terra. Quatro homens com camisa do mesmo tecido do vestido, calça jeans e chapéu de palha, tocam os instrumentos, cantam e batem palmas, indo ao encontro do grupo de mulheres para dançar com elas em alguns momentos.

A história dos moradores também está sendo mote para a criação de um museu comunitário na ilha. O morador da casa mais antiga, Sr. Salvador, está construindo uma nova residência para que a outra abrigue os objetos e as memórias do povoado (Figura 4). Uma imensa canoa de pescador emborcada no quintal faz parte do acervo a ser musealizado (entrevista informal realizada em 2016).

Um Museu Comunitário na geografia do Turismo de Base Comunitária casa-se perfeitamente com as noções de planejamento e gestão do turismo, em sua relação com o associativismo, cooperativismo, agentes sociais, arranjos socioprodutivos e a

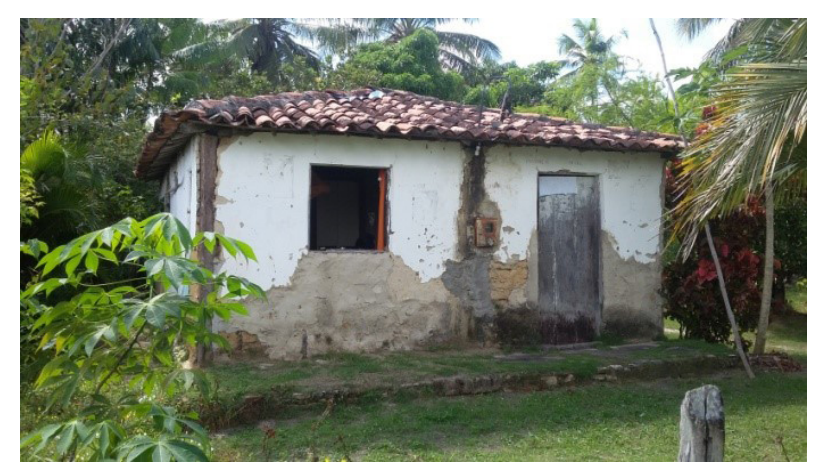

Figura 4: Casa mais antiga da Ilha Mem de Sá (futuro Museu Comunitário)

Fonte: Foto JCM, 2016. economia solidária, visando ao desenvolvimento endógeno, uma vez que:

[...] o grupo que dirige o museu é uma instância organizada da comunidade, seja vinculada ao governo local, seja constituído como organização não governamental. Através do tempo, permite gerar habilidades, experiência e recursos sociais que fortalecem a capacidade para a autonomia. A forma como constrói forças está em relações horizontais, no interior da comunidade e também fora dela (Lersch; Ocampo, 2008, p.4).

A ideia do desenvolvimento de uma economia solidária na qual as demandas de sustentabilidade sejam viabilizadas por meio da cultura funciona como lócus de visibilidade, afirmação identitária e agregação de valor ao patrimônio local. Conforme o IBRAM (2014, p.45): "Os museus brasileiros fazem parte desse universo de atrativos turísticos e são potenciais indutores de visitações”, capazes de dinamizar a produção artesanal, a gastronomia, a hospitalidade, dentre outros serviços ofertados pela comunidade.

Em fevereiro de 2017, as equipes do Programa de Desenvolvimento do Turismo (Prodetur), programa integrado à Secretaria de Estado do Turismo (Setur), a Secretaria de Estado do Meio Ambiente e Recursos Hídricos (Semarh), Embrapa e Capitania dos Portos da Marinha, reuniram os moradores para uma consulta pública a respeito da iniciação do processo licitatório para a construção dos atracadouros do povoado Caibros e Ilha Mem de Sá (Prefeitura de Itaporanga, 2017).

Essa etapa é exigida pelo Banco Interamericano de Desenvolvimento (BID) para a iniciação da obra com um investimento de mais de $\mathrm{R} \$ 2,2$ milhões do Prodetur (Prefeitura de Itaporanga, 2017). De acordo com a secretária da Associação de Moradores da Ilha de Mem de Sá, Ângela Maria Santos:

A expectativa dos moradores é grande com relação a obra, porque eles esperam a melhoria da condição de vida deles, que é ter mais qualidade de vida dentro do que eles sabem fazer, que é explorando o que nós temos e o que nós sabemos desenvolver. Pra mim, esse encontro de hoje foi bem produtivo, porque discutimos algumas coisas que 
estavam gerando um burburinho e foi esclarecido, encontramos parceiros para que junto com a associação possamos desenvolver melhor as ações sem muitos questionamentos (Prefeitura de Itaporanga, 2017).

O TBC da ilha Mem de Sá reafirma que na contemporaneidade os residentes não querem mais apenas a "informação de cima para baixo", mas sim o estabelecimento de um processo dialógico, que interfira no planejamento, tome parte nas decisões, coloque suas dúvidas, afirme o que gosta e o que não gosta no processo de desenvolvimento econômico de sua área de moradia.

Sua cultura, quando integrada ao planejamento turístico, tendo os meios financeiros para tal, fortalece sua disposição para a manutenção de memórias e estímulo aos mais jovens. Para isso, as políticas culturais e as políticas públicas de ordem estruturais são fundamentais.

\section{Considerações Finais}

A visão romântica da cultura que mantém um povo ligado à sua terra, que está solidificada nos elos de transmissão familiar sem a percepção de um retorno financeiro, tem se fragmentado frente aos efeitos da globalização com ofertas sedutoras de ganho econômico. A economia, portanto, torna-se emblemática para repensar esse quadro.

A criatividade que emana de comunidades produtoras de cultura quando inseridas na lógica de circulação e distribuição da economia da cultura promove o interesse na preservação dos modos de saber, das tradições e das biografias de moradores que antes sentiam-se muitas vezes excluídos da história de grandes personagens e datas.

Por isso a economia criativa lida em grande parte com o intangível, o imaterial, todavia, repleto de valor simbólico, mas que dentro de um planejamento adequado agrega valor monetário e a sustentabilidade dos produtores de cultura.

Mais do que uma determinação de mercado, a Economia da Cultura inspira Políticas Públicas presentes em Editais e iniciativas co-gerenciadas pelo poder público e as comunidades (na figura de Ministérios e Secretarias de Cultura, Turismo, Planejamento e Desenvolvimento). Entretanto, apesar de um maior empenho na captação de recursos financeiros advindos de fontes públicas e privadas, as disparidades regionais ainda ocasionam uma maior concentração de fomento no eixo centro-sul do país.

O quadro comparativo de investimentos em cultura nas capitais brasileiros, no último decênio, traz transparência à administração pública e mobiliza os grupos civis organizados em suas reivindicações.

Em Sergipe, Aracaju, embora revele um fraco investimento financeiro em cultura por parte de seus governos locais, sua colocação à frente de cidades como Rio de Janeiro, Fortaleza, João Pessoa e Salvador - conforme os dados do Tesouro Nacional - evidencia tanto o papel de acordos políticos intrapartidários, bem como a organização institucional em torno de Conferências e Planos de Cultura municipais e estaduais.

Ressaltam-se ainda os investimentos realizados peloMinistério do Turismoem obras de infraestrutura turística que culminaram em melhorias significativas na ligação rodoviária entre Aracaju e seu litoral sul, bem como nas cidades interioranas de Estância/ Indiaroba e o estado da Bahia.

Também a região do rio São Francisco recebeu financiamentos direcionados ao desenvolvimento sustentável, pesquisas e marketing turístico. Esses recursos chegaram até a Ilha Mem de Sá, que desde 2008 é reconhecida por projetos de economia participativa via Turismo de Base Comunitária alicerçados em editais públicos e parcerias com instituições federais educacionais.

O turismo de base comunitária tem se revelado um caminho interessante para o empoderamento das comunidades que aprendem a gerir tanto os problemas quanto as soluções no desenvolvimento econômico de seus povoados. A saída do eixo da massificação, para uma experiência de imersão cultural atrai um segmento desejoso do encontro com o patrimônio cultural em toda sua vitalidade.

A socialização das estatísticas de investimentos e cultura, o apoio aos projetos de restauração e revitalização dos monumentos históricos, os planos de desenvolvimento integrado do turismo sustentável ensejam políticas institucionais essenciais para o retorno social dos impostos pagos aos governos pela sociedade, afirmando o exercício cidadão.

Um planejamento turístico consciente faz uso destes dados e cobra o compromisso de gestores na 
conservação, melhoria e ampliação dos atrativos turísticos culturais.

Claro que conflitos, problemas e tensões sempre existirão, mesmo porque há imensas desigualdades entre grupos, entre regiões, entre perspectivas de governabilidade, entretanto, ao levar a cultura para o placo da economia, entre gritos e tambores, existirá sempre a disposição de se construir mais pontes do que abismos.

\section{Referências}

Barbalho, A. (2015). Por um conceito de política cultural. In: Cristina Schmidt; Rosália Maria Netto Prados; Heloisa Araújo Duarte Valente. (Org.). Mídia e políticas culturais. 1ed. (p. 28-38). São Paulo: Ícone, v. 1.

Bartholo et al (Orgs.) (2009) Turismo de Base Comunitária: diversidade de olhares e experiências brasileiras. Rio de Janeiro: Letra e Imagem. Disponível em: http://www.ivt-rj.net/ivt/bibli/Livro\%20TBC.pdf, Acesso em: 14/01/2017.

Bayardo, R. (2013). Indústrias criativas e políticas culturais. Perspectivas a partir do caso da cidade de Buenos Aires. In: Calabre, Lia (org.). Políticas culturais: informações, territórios e economia criativa. Tradução de Carmen Carballal. São Paulo: Itaú Cultural; Rio de Janeiro: Fundação Casa de Rui Barbosa.

Burgos, A. \& Mertens, F. (2015). Os desafios do turismo no contexto da sustentabilidade: as contribuições do turismo de base comunitária. Revista do Turismo y Patrimomio Cultural. Vol. 13 (1): 57-71. Disponível em file://C:/Users/100-6110/Downloads/texto\%20 1\%20TBC.pdf, Acesso em: 15/01/2017.

Canclini, N. G. (2001). Definiciones en transición. Buenos Aires: CLACSO.

Coallier, F. (2016). A systems Engineering perspective to Smart City IT Standards. In: Smart City Seminar. Singapura: ITSC.

Coelho Neto, J. T. (1997). Dicionário Crítico de Política Cultural. São Paulo: Iluminuras.

Costa, F. R. (2014). Turismo e patrimônio cultural. Interpretação e qualificação. São Paulo: Ed. SENAC e Edições SESC.

Diogo, E. (org.) (2009). Recuperação de Imóveis Privados em Centros Históricos. Brasília, DF: Iphan/Programa Monumenta.

Empresa Brasileira de Pesquisa Agropecuária [EMBRAPA - Tabuleiros Costeiros] (2007). Gestão Participativa para o Desenvolvimento da Comunidade Mem de Sá - Itaporanga D'Ajuda/SE. Aracaju: Embrapa Tabuleiros Costeiros.

Getino, O. (2003). Las industrias culturales en el MERCOSUR. Apuntes para un proyecto de política de Estado. In: A.A.V.V. Industrias Culturales: mercado y políticas públicas en Argentina. Buenos Aires: Ediciones CICCUS - Secretaría de Cultura de la Nación.

Instituto Brasileiro de Museus [IBRAM] (2014). Museu e Turismo: estratégias de cooperação. Brasília, DF: IBRAM.

International Council of Monuments and Sites [ICOMOS] (1976). Carta de Turismo Cultural. Disponível em: http://portal.iphan.gov.br/uploads/ ckfinder/arquivos/Carta\%20de\%20Turismo\%20 Cultural\%201976.pdf, Acesso em: 15/01/2017.

Machado, J. (2009). A contribuição do Monumenta para a experiência brasileira de financiamento à habitação em sítios históricos. In: Diogo, E. (org.) Recuperação de Imóveis Privados em Centros Históricos. Brasília, DF: Iphan/Programa Monumenta, p.9-14.

Lersch, T. M. \& Ocampo, C. C. (2008). O conceito de museu comunitário: história vivida ou memória para transformar a história? Disponível em: http://www. abremc.com.br/pdf/5.pdf, acesso em: 05/02/2017.

Mankiw, N. G. (2013). Introdução à Economia. São Paulo: Cengage Learning.

Ministério da Cultura [MinC] (2015). Instrução Normativa $\mathrm{n}^{\circ}$ 001, de 25 de Março de 2015. Brasília: IPHAN/Gabinete da Presidência, Disponível em: http://portal.iphan.gov.br/uploads/ ckfinder/arquivos/Instrucao_normativa_01_2015. pdf, Acesso em: 03/06/2017.

Ministério do Planejamento, Desenvolvimento e Gestão [MP] (2015). PAC Relatório do $1^{\circ}$ Balanço 2015. Brasília: MP.

Ministério do Turismo [MTur] (2010). Dinâmica e diversidade do turismo de base comunitária: desafio para a formulação de política pública/Ministério do Turismo. Brasília: Ministério do Turismo.

Ministério do Turismo [MTur] (2012). Os números de Sergipe. Estado recebe apoio do MTur para incrementar a atividade turística. Disponível em: http://www.turismo.gov.br/ultimas-noticias/3526os-numeros-de-sergipe.html, Acesso em: 03/06/2017.

Peters, B. G. (1986). American Public Policy. Chatham, N.J.: Chatham House.

Prefeitura de Itaporanga (2017). Prodetur realiza consulta pública na Ilha Mem de Sá. Em pauta, início das obras do atracadouro. Infonet. Disponível em: http://www.infonet.com.br/noticias/economia/ ler.asp?id=196729, Acesso em: 03/06/2017.

Reis, A. C. F. (2008). Economia criativa: como estratégia de desenvolvimento: uma visão dos países em desenvolvimento. São Paulo: Itaú Cultural.

Reis, A. C. F. (2012). Economia da cultura: Entrevista com Ana Carla Fonseca Reis. Portal da Secretaria da Cultura do Rio Grande do Sul. Disponível em: http:// www.cultura.rs.gov.br/v2/2012/01/economia-dacultura-entrevista-com-ana-carla-fonseca-reis/, 
Acesso em: 02/06/2017.

Reis, A. C. F. \& MARCO; K. (orgs) (2009). Economia da cultura: ideias e vivências. Rio de Janeiro: Publit.

Rocha, A. (2009). Economia da Cultura e Desenvolvimento. In: REIS, Ana Carla Fonseca; MARCO; Kátia de (orgs). Economia da cultura: ideias e vivências. (p.39-46). Rio de Janeiro: Publit.

Souza, C. (2006). Políticas Públicas: uma revisão da literatura. Sociologias, Porto Alegre, ano 8 (16): 2045. Disponível em: http:/www.scielo.br/pdf/soc/ n16/a03n16, Acesso em: 02/06/2017.

Technum Consultoria (2013). Polo Costa dos Coqueirais. Revisão do Plano de Desenvolvimento Integrado do Turismo Sustentável. Produto 5. Versão Final. Vol. II - Documento Técnico. Brasília: Technum
Consultoria SS.

Zallo, R. (1988). Economía de la comunicación y la cultura. Madri: Editorial Akal.

\section{Contribuição dos autores na construção} do artigo

MELLO: Introdução, discussão teórica e considerações finais.

SILVA: Estudo de caso da Ilha Mem de Sá.

FAXINA: Coleta de dados quantitativos, revisão e resumos 